\title{
Motor Task Performance under Visual and Auditory Feedback Post Stroke: A Randomised Crossover Trial
}

\section{Fernando Dias Correia $^{1 *}$, Filipe Santos ${ }^{2}$, André Branquinho², André Nogueira ${ }^{2}$, Cátia Candeias ${ }^{3}$, Patrick Quintaneiro $^{3}$, António Almeida ${ }^{3}$ and} Virgilio Bento ${ }^{4}$

${ }^{1}$ Neurology Department, Hospital de Santo António- Centro Hospitalar do Porto, Porto, Portugal

${ }^{2} S W O R D$ Health, Porto, Portugal

${ }^{3}$ CMM Aveiro, Portugal

${ }^{4}$ University Institute of Maia - ISMAI, Maia, Portugal

\begin{abstract}
Background: Biofeedback tools have been used in stroke rehabilitation to improve motor performance. In a previous study, we tested a biofeedback system based on inertial motion trackers, coupled with a vibratory module. Limitations of vibratory feedback, combined with data showing efficacy of combining visual and auditory feedback, justified changing the biofeedback.
\end{abstract}

Objective: Follow-up study to assess whether visual and auditory feedback could improve motor performance of patients after stroke.

Methods: Randomised controlled study (NCT03032692) involving 30 patients. Participants were allocated to two groups; both performed one exercise with the affected upper-limb with and without biofeedback. Primary outcome was the number of correct movements, defined as those starting at the baseline and reaching the target joint angle, without violating movement or posture constraints.

Results: The number of correct movements was higher in the sessions with feedback by an average of 13.2 movements/session (95\% Cl [5.9; 20.4]; $\mathrm{P}<0.01)$ and movement error probability was decreased from 1.3:1 to 7.7:1.

Conclusions: This study corroborates published data on the benefits of visual and auditory feedback. This feedback appears superior to the vibratory feedback, allowing more information to be presented to the patient, increasing the focus in movement quality. Further investigation is needed to confirm clinical benefits.

Keywords: Visual; Auditory; Feedback; Rehabilitation; Stroke

\section{Introduction}

Stroke is one of the main causes of disability worldwide [1]. About $80 \%$ of patients with stroke experience motor weakness/hemiparesis [2] and the prevalence of hemiparesis 6 months after is about $50 \%$ [3]. Whilst there is evidence for benefit following an early start [4], continuation of physiotherapy late after stroke also appears beneficial [5]. Ensuring access to continue rehabilitation is therefore essential, but not sufficient, as evidence highlights the need for highly-intensive, repetitive task-specific practice with feedback on performance [6].

Despite this evidence, there is a huge unmet need in stroke rehabilitation [6-9]. As such, low-cost solutions that democratize access, increase treatment intensity and enable independent use are much needed. To overcome these problems, new technological solutions are being developed. Robotic devices [10-12] have demonstrated improvements in motor impairment [10-12], but are bulky, complex and costly, which limits both home-use and widespread application [13]. Camera-based solutions, in particular those based on Microsoft Kinect, have been widely adopted [14], as well as those based on the Nintendo Wii console [15,16]. While practical, these systems have limitations regarding the accuracy in full kinematic movement tracking [14,17].

To overcome the shortcomings of these systems, we have tested a novel and low-cost kinematic biofeedback tool (SWORD) based on inertial motion units (IMUs). Despite the high precision [18-20], IMUs have only been used so far to quantify and characterize movement patterns and effects of interventions in post-stroke patients [19-21], with only anecdotal evidence of their use in rehabilitation tools [22-24].

The first version of the system provided vibratory feedback through a device placed on the patient's wrist. This version was tested in a singlecenter randomised control study, involving 44 patients [25]. This study was aimed at exploring the impact of the system on the performance of a simplified version of the hand-to-mouth task (shoulder flexion with elbow flexion at $90^{\circ}$ ) on one exercise session. The results showed that the vibratory feedback was able to modulate motor training, increasing the number of correct movements and reducing the probability of performing errors in motor tasks [25].

Subsequently, the vibratory feedback was replaced for real-time visual and auditory feedback. This decision was made taking into account: a) neurobiological data showing increased functional activity in several cortical areas after stroke [26]; b) a multimodal approach implies activation and coordination of several cortical regions, stimulating neuroplasticity[27]; c) research findings suggest that visual and auditory feedback may enhance patient performance[28]; d)intrinsic limitations of vibratory feedback in patients with sensory impairment; e) vibratory feedback was not sufficient to relay all the required kinetic information; f) the vibratory module could interfere with system accuracy.

A follow-up study, with a similar methodology, was then planned to test the new feedback on the motor performance of patients after

*Corresponding author: Fernando Dias Correia, Largo Prof. Abel Salazar, Porto, Portugal, Tel: +351966557789; E-mail: fanacorreia@gmail.com

Received October 16, 2017; Accepted October 26, 2017; Published October 31, 2017

Citation: Correia FD, Santos F, Branquinho A, Nogueira A, Candeias C, et al (2017) Motor Task Performance under Visual and Auditory Feedback Post Stroke: A Randomised Crossover Trial. Int J Neurorehabilitation 4: 291. doi: 10.4172/23760281.1000291

Copyright: () 2017 Correia FD, et al. This is an open-access article distributed under the terms of the Creative Commons Attribution License, which permits unrestricted use, distribution, and reproduction in any medium, provided the original author and source are credited. 
stroke. We hypothesized that this new feedback would have a positive impact on motor performance (defined by an increase in the number of correct movements) and that the magnitude of the effect would be at least similar to the vibratory feedback tested in the previous study.

\section{Methods}

\section{Study design}

Non-blind, two-session, crossover study, randomised between experiment-active comparator and active comparator-experiment (1:1), conducted in three outpatient rehabilitation clinics: CMM: Centro Médico da Murtosa; CMM: Centro Médico de Aveiro and Centro Médico de Viseu.

\section{Sample size estimate}

In a previous study [25], the number of correct movements per minute in the sessions performed with feedback was $25.7(\mathrm{SD}=11.7)$ and in the sessions without feedback was $18.5(\mathrm{SD}=11.4)$ - corresponding to a $38.9 \%$ increase in correct movements. Considering a power of $80 \%$ and a two-sided 0.05 significance level, 39 patients would be necessary to detect a similar difference in this study. Preliminary data collected on the effect of the audiovisual feedback before the present study (unpublished), supported a greater effect, and therefore sample size was limited to 30 patients, an adequate size to detect a $45 \%$ increase in correct movements.

System technical specifications
The version of the system used in this study was composed of the following interconnected components (Figures 1A-1C): a) inertial motion trackers; b) mobile App; c) web-based Portal (not shown).

The motion trackers are placed on body segments using Velcro straps (Figure 1B), each in a specific position (Figure 1D):

- Red tracker (I): Over the sternum, approximately midway between the manubrium and the xiphoid process.

- Green tracker (II): On the lateral surface of the arm, approximately midway between the achromium and the elbow.

- Blue tracker (III): On the midline of the dorsal surface of the wrist in the sessions with feedback, the following information was relayed to the patient in real time:

- Visual feedback (Figure 1B): Bar displaying the progress in each one of the movements, in relation to the specified goal; repetition count; remaining exercise time; posture

- Auditory feedback: "Positive" sign each time the patient performed a correct repetition; "negative" sign each time the patient performed an incorrect repetition; "alarm" sign in case of inactivity (period without detectable movement $>2 \mathrm{x}$ execution time recorded in the baseline session.

\section{Participants}

Patients over 18 years of age, previously independent, with a

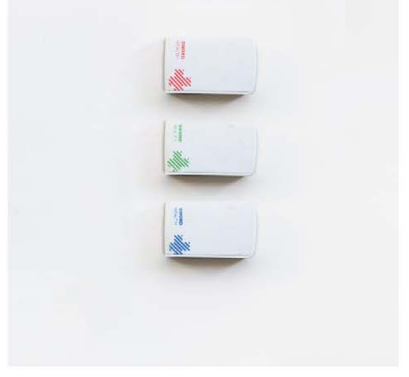

Figure $1 \mathrm{~A}$
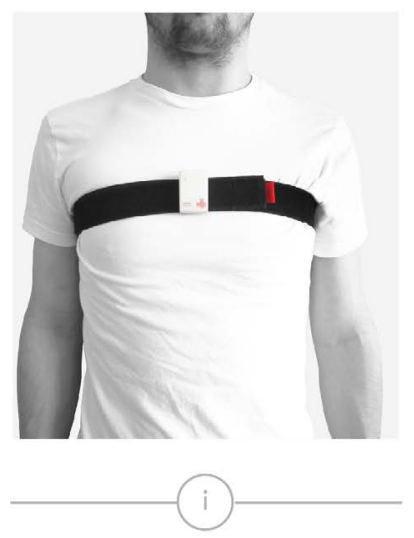

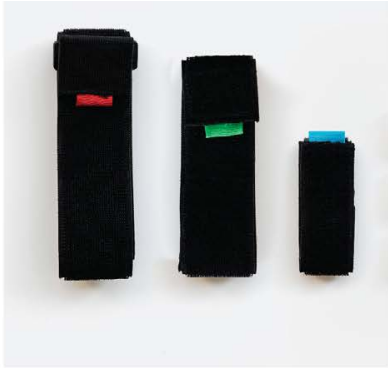

Figure 1B

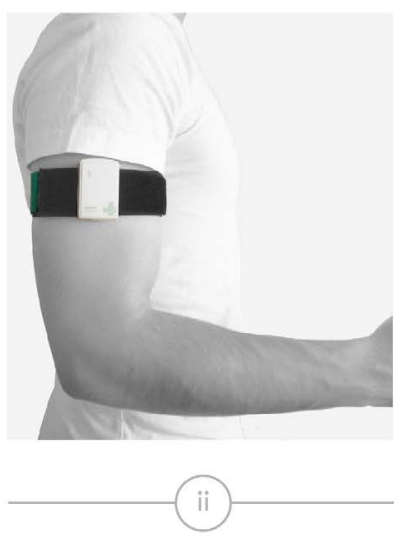

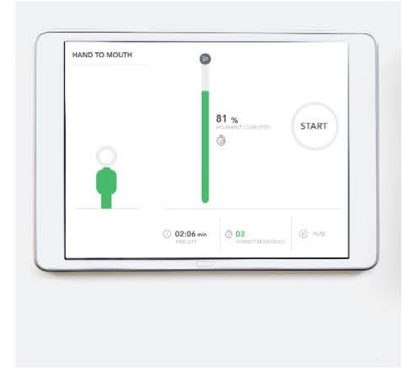

Figure $1 \mathrm{C}$

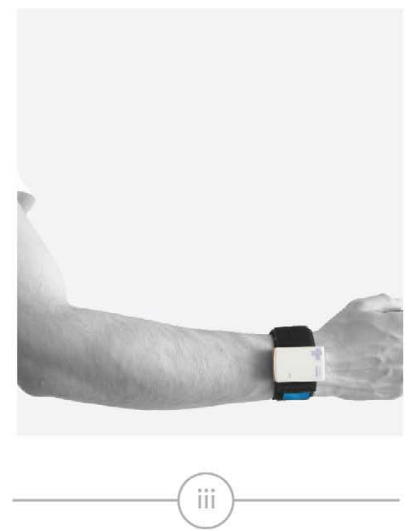

Figure 1D

Figure 1: System components. (A) IMUs placed in each segment allow determination of the special orientation of the limb. (B) The IMUs are secured to the patient through elastic Velcro ${ }^{\circledR}$ straps. (C) The mobile app provides information on the exercise and real-time visual and auditory feedback. (D) Tracker placement: I) red tracker; II) Green tracker; III) Blue tracker. 
Modified Rankin Scale (mRS) [29] score of 0-1 and admitted for rehabilitation after a first-time ischemic stroke were screened for study eligibility between $1^{\text {st }}$ June and $31^{\text {st }}$ August of 2016.

Participants were included if they had: 1) clinical symptoms and signs and CT or MRI findings compatible with a lesion in the territory of the Medial Cerebral Artery (MCA) - assessed by a neurologist; 2) persistent motor deficit on the upper limb but not plegia with a score between 0 and 2 on item $5 b$ of the National Institute of Health Stroke Scale (NIHSS) [30]; 3) more than 2 weeks after stroke onset; and 4) the ability to sit comfortably for more than 10 minutes and perform twostep commands.

Subjects were excluded if they had: 1) no detectable motor deficits at baseline assessment; 2) severe aphasia; 3) clinical dementia or Mini Mental State Examination (MMSE) [31] below cutoff; 4) other cognitive or psychiatric comorbidity that impaired communication or compliance with the tasks; 5) severe respiratory or cardiac condition incompatible with more than 5 minutes of continuous mild exercise in a sitting position; 6) pain or deformity that limited upper limb movement on the affected side.

\section{Randomization}

Eligible participants were randomly allocated in a 1:1 ratio to two study arms, using an online randomizer (https://www.randomizer.org). Balance between arms was guaranteed using random permuted blocks of two. Randomization was performed by FDC and communicated to the investigators responsible for data acquisition only after patient enrollment.

To avoid carry-over effects due to fatigue or learning, randomization of the session order was performed. Group 1 performed the exercise with biofeedback first and without biofeedback after, with an interval $>24$ h. Group 2 performed the exercise in the opposite order.

\section{Blinding}

The nature of the study does not allow blinding of the patients regarding biofeedback status during the sessions. However, the participants were blinded to the primary and secondary movement outcomes being measured. Statistical analysis was performed blinded for experimental or active comparator status.

\section{Baseline measures}

Participant characterization included: a) demographics; b) educational level; c) antecedent and comorbid conditions; pre-morbid mRS score; d) MMSE; e) stroke description: date of onset; type; territory involved; NIHSS score.

For each patient, a baseline movement characterization was performed. This consisted of asking the patient to perform three repetitions of the desired movement to the best of his ability, while SWORD was recording movement parameters. Baseline and maximum shoulder flexion angles were determined for each repetition and used to set movement goals (median of the 3 repetitions +5 degrees for the baseline and -5 degrees for the target). Two additional repetitions were performed to confirm accuracy and reproducibility. Posture deviation during execution was measured and used to calculate a maximum allowed posture threshold for each patient (recorded posture deviation +10 degrees).

\section{Intervention}

Patients were randomized in two groups. Both performed two separate sessions consisting of one exercise -shoulder flexion with elbow flexion at 90 degrees - for $4 \mathrm{~min}$ in both experimental settings: with and without biofeedback. Patients were instructed to perform as many movements as possible in the allocated time, at a comfortable pace, starting at or below the baseline and trying to reach maximum flexion without excessive pain or discomfort. At the end of each session, patients were asked to graduate pain and fatigue using scales graded from 0 to 10 .

SWORD was used to record movement data in both sessions. Movement constraints were imposed to detect movements different from shoulder flexion and/or patient compensation. These constraints did not exist in the previous version, increasing the difficulty of achieving a correct repetition and forcing the patient to concentrate on performing the movement correctly.

The constraints used in this study were the following: a) elbow flexion between $40^{\circ}$ and $140^{\circ}$; b) shoulder abduction between $-40^{\circ}$ and $60^{\circ}$ (when shoulder flexion is between $-45^{\circ}$ and $45^{\circ}$ ); c) shoulder abduction between $120^{\circ}$ and $180^{\circ}$ (when shoulder flexion is between $135^{\circ}$ and $180^{\circ}$ ); d) shoulder abduction between $-120^{\circ}$ and $-180^{\circ}$ (when shoulder flexion is between $-135^{\circ}$ and $\left.-180^{\circ}\right)$; e) horizontal shoulder abduction between $-30^{\circ}$ and $50^{\circ}$ (when shoulder flexion is between $45^{\circ}$ and $135^{\circ}$ ); forearm with an angle relative to the axial plane between $-50^{\circ}$ and $50^{\circ}$ (when shoulder flexion is between $45^{\circ}$ and $135^{\circ}$ ); forearm with an angle relative to the coronal plane between $-50^{\circ}$ and $50^{\circ}$ (when shoulder flexion is between $45^{\circ}$ and $135^{\circ}$ ).

Correct movements were defined as those starting at or below the recorded baseline and reaching or surpassing the maximum flexion angle set as goal, without violating movement or posture constraints.

Incorrect movements were defined as those not reaching the goal, violating movement constraints or exceeding the posture deviation threshold. Pauses were defined as interruptions in movement with duration superior to the mean execution time (time from baseline to maximum flexion angle) of that patient plus two standard deviations.

\section{Primary and secondary outcomes}

The primary outcome was the total number of correct movements performed during the session, as determined automatically by the device.

Secondary outcomes were: a) total number of movements; b) number of incorrect movements; c) number of consecutive incorrect movements; d) number of pauses; e) posture errors; g) movement frequency; h) range of motion of correct movements (difference between maximum and baseline shoulder flexion angles (in degrees); i) range of motion variability over time.

\section{Safety}

Pain and fatigue scores were collected at the end of each session and by patient report of other adverse events.

\section{Statistical Analysis}

To assess differences in clinical and demographic variables of both arms, independent samples T test, Mann-Whitney U test, Chi-squared test and Fisher exact tests were used.

For comparison of primary and secondary outcomes between the two sessions paired samples $\mathrm{T}$ test and Chi-square test were used.

For the comparison of primary outcome within subgroups, paired samples $\mathrm{T}$ test and Mann-Whitney $\mathrm{U}$ tests were used. 
The influence of demographic and clinical characteristics in the primary outcome was explored through multivariate regression analysis.

Correlations between demographic and clinical characteristics and study outcomes were explored using Pearson correlation for continuous variables and Spearman rank test for ordinal variables.

Statistical analysis was performed with IBM $^{\circ}$ SPSS ${ }^{\circ}$ Statistics v23 and the limit for a type I error in two-tailed tests was 0.05 .

\section{Results}

Forty-nine patients were assessed for eligibility between June and August 2016 (Figure 2) and 19 were excluded. Reasons for exclusion were: a) hemorrhagic stroke $(n=7)$; b) posterior circulation infarct $(n=4) ; c)$ plegia $(n=6)$ and d) severe aphasia $(n=2)$.

Thirty patients were included and randomized to two study arms (15 patients each). Mean age of the participants was 65.3 years ( $\mathrm{sd}=12.6$; range $38-86$ years), $73.3 \%$ were male; average education was 4.7 years ( $\mathrm{sd}=3.5$; range $0-15$ years) and average time from stroke onset was 203 days ( $\mathrm{sd}=189$; range $15-756$ days). In $83.3 \%$ of cases, the stroke involved the left MCA territory. Median NIHSS at randomization was 3.0 (range 0-9; inter-quartile range 3.0); 73.3\% had a modified Rankin scale (mRS) score of 1 or 2 and $26.6 \%$ a mRS score of 3 or 4 . Baseline characteristics of study participants are summarized in Table 1, divided by randomization group. There were no significant differences between groups.

All participants were able to complete both sessions. The results are summarized in Table 2 .

\section{Primary outcome}

In the sessions with feedback, the number of correct movements was higher $(\mathrm{p}<0.01)$, with an average number of correct movements of $59.7(\mathrm{sd}=27.8)$ in the sessions with feedback and $47.3(\mathrm{sd}=19.6)$ in the sessions without feedback (Table 2).

Between the two sessions, there was a mean difference of 13.2 movements per session, favoring the sessions with feedback $(\mathrm{sd}=19.4$; $95 \%$ CI $[5.9 ; 20.4]$ ), corresponding to an average increase of 3.3 correct movements per minute (sd=4.85 CI $[1.5 ; 5.1])$ (Figures 3A and 3B).

\begin{tabular}{|l|c|c|c|c|}
\hline & Total & $\begin{array}{c}\text { Session without } \\
\text { feedback first }\end{array}$ & $\begin{array}{c}\text { Session with } \\
\text { feedback first }\end{array}$ & P value \\
\hline Number of patients & 30 & 15 & 15 & - \\
\hline $\begin{array}{l}\text { Age } \\
\text { Years, average (sd) }\end{array}$ & $65.3(12.6)$ & $64.5(13.9)$ & $66.0(11.5)$ & $0.76^{*}$ \\
\hline $\begin{array}{l}\text { Gender } \\
\text { Male (\%) }\end{array}$ & 73.3 & 80.0 & 66.7 & $0.68^{* *}$ \\
\hline $\begin{array}{l}\text { Education } \\
\text { Years, average (sd) }\end{array}$ & $4.7(3.5)$ & $4.5(3.8)$ & $4.8(3.2)$ & $0.81^{* * *}$ \\
\hline $\begin{array}{l}\text { Stroke side } \\
\text { Left side (\%) }\end{array}$ & 83.3 & 86.7 & 80.0 & $1.00^{* *}$ \\
\hline $\begin{array}{l}\text { Time from onset } \\
\text { Days, average (sd) }\end{array}$ & $\begin{array}{c}202.8 \\
(189.6)\end{array}$ & $205.3(209.1)$ & $200.3(175.0)$ & $0.94^{* * *}$ \\
\hline $\begin{array}{l}\text { NIHSS Score } \\
\text { Median (Range; IQR) }\end{array}$ & $3.0(0-9 ; 3)$ & $2.0(0-6 ; 3)$ & $4(0-9 ; 3)$ & $0.07^{* * *}$ \\
\hline $\begin{array}{l}\text { mRankin at } \\
\text { randomization } \\
\text { Median (range) }\end{array}$ & $2(1-4 ; 3)$ & $2(1-3 ; 0)$ & $2(1-3 ; 2)$ & $0.87^{* * *}$ \\
\hline
\end{tabular}

*: Independent samples T test; **: Fisher's exact test; ***: Mann-Whitney test Table 1: Baseline characteristics of study participants.

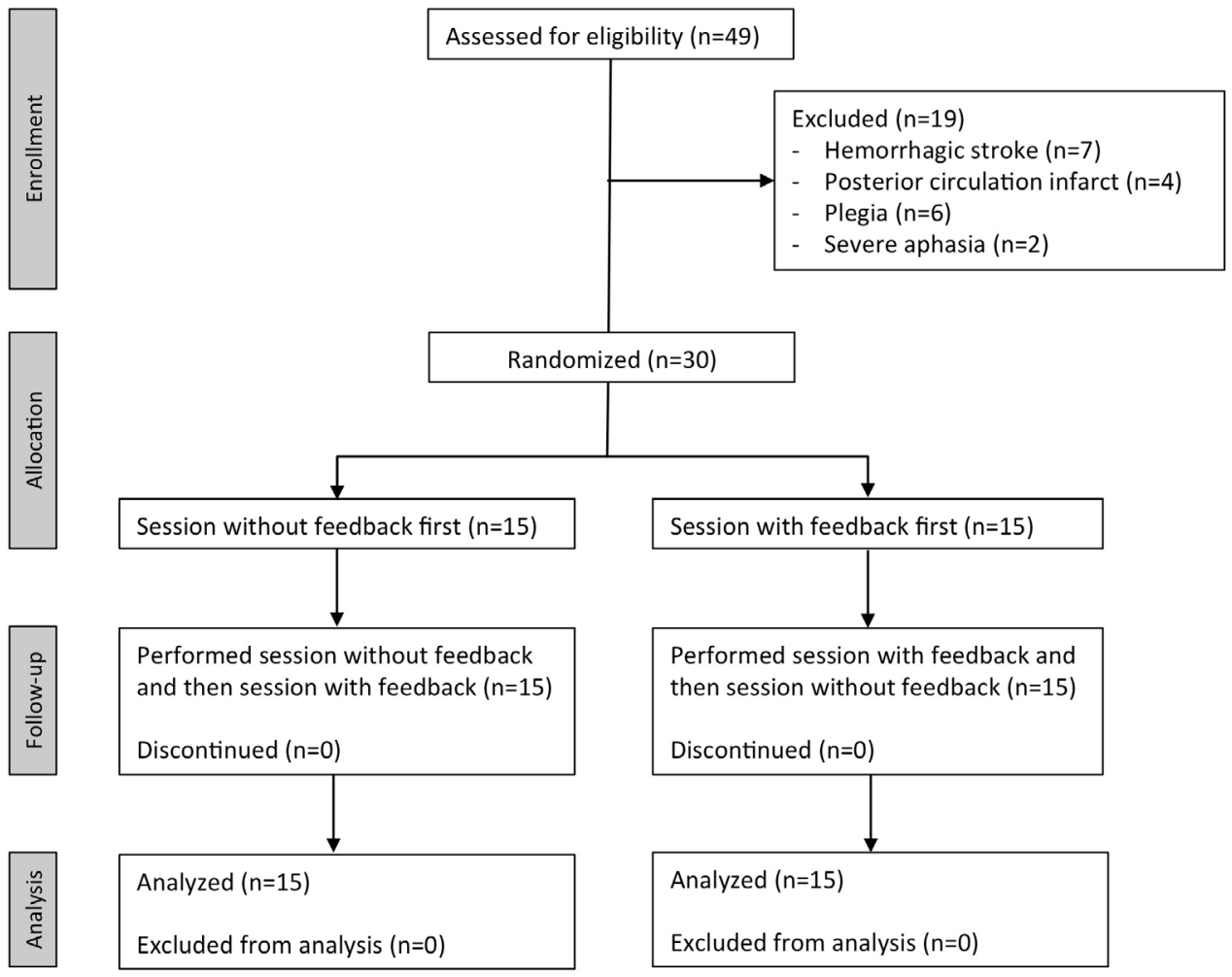

Figure 2: Study flowchart and CONSORT diagram. 


\section{Secondary outcomes}

With feedback, the number of incorrect movements was lower $(\mathrm{p}=0.03)$, with an average number of incorrect movements of 5.0 $(\mathrm{sd}=27.8 \mathrm{CI}[2.4 ; 7.5])$ in the sessions with feedback and $30.5(\mathrm{sd}=31.0$ CI $[18.9 ; 42.1]$ ) in the sessions without feedback (Table 2).

\begin{tabular}{|c|c|c|c|}
\hline & $\begin{array}{l}\text { Without } \\
\text { feedback }\end{array}$ & With feedback & $P$ value \\
\hline $\begin{array}{l}\text { Number of movements } \\
\text { Average (SD) }\end{array}$ & $59.7(27.8)$ & $47.3(19.6)$ & $<0.01^{*}$ \\
\hline $\begin{array}{l}\text { Number of correct movements } \\
\text { Average (SD) }\end{array}$ & $29.2(21.0)$ & $42.4(20.3)$ & $<0.01^{*}$ \\
\hline $\begin{array}{l}\text { Number of incorrect movements } \\
\text { Average (SD) }\end{array}$ & $30.5(31.0)$ & $5.0(6.8)$ & $0.03^{*}$ \\
\hline $\begin{array}{l}\text { Max consecutive wrongs } \\
\text { Average (SD) }\end{array}$ & $17.7(22.5)$ & $1.7(1.7)$ & $0.06^{*}$ \\
\hline $\begin{array}{l}\text { Range of motion of correct } \\
\text { movements (degrees) } \\
\text { Average (SD) }\end{array}$ & $\begin{array}{c}76.1(\mathrm{sd}=25.0 \mathrm{Cl} \\
[68.6 ; 90.0])\end{array}$ & $\begin{array}{c}76.0(\mathrm{sd}=24.3 \\
\mathrm{Cl}[66.8 ; 85.0])\end{array}$ & $0.98^{*}$ \\
\hline \multicolumn{4}{|l|}{$\begin{array}{l}\text { Range of motion variability of } \\
\text { correct movements } \\
\text { Average (SD) }\end{array}$} \\
\hline Between $1^{\text {st }}$ and $2^{\text {nd }}$ mine & $2.8(9.7)$ & $1.6(6.5)$ & $0.57^{*}$ \\
\hline Between $2^{\text {nd }}$ and $3^{\text {rd }} \min$ & $0.2(6.9)$ & $0.5(5.6)$ & $0.83^{*}$ \\
\hline Between $3^{\text {rd }}$ and $4^{\text {th }} \min$ & $0.7(4.6)$ & $1.4(7.4)$ & $0.72^{*}$ \\
\hline $\begin{array}{l}\text { Movement frequency } \\
\mathrm{Hz} \text {, average (SD) }\end{array}$ & $0.3(0.1)$ & $0.2(0.1)$ & $<0.01^{*}$ \\
\hline $\begin{array}{l}\text { Number of pauses } \\
\text { average (SD) }\end{array}$ & $0.2(0.7)$ & $0.3(0.5)$ & $0.43^{*}$ \\
\hline $\begin{array}{l}\text { Posture errors } \\
\text { average (SD) }\end{array}$ & $7.6(14.4)$ & $2.4(3.3)$ & $0.76^{*}$ \\
\hline Pain n (\%) & & & $0.75^{\star *}$ \\
\hline No pain & $21(70.0)$ & $23(76.7)$ & \\
\hline Mild (1-3) & $4(13.3)$ & $3(10.0)$ & \\
\hline Moderate (3-6) & $4(13.3)$ & $2(6.7)$ & \\
\hline Severe $(7-10)$ & $1(3.3)$ & $2(6.7)$ & \\
\hline Fatigue N (\%) & & & $0.40^{* *}$ \\
\hline No Fatigue & $5(16.7)$ & $8(26.7)$ & \\
\hline Mild (1-3) & $14(46.7)$ & $8(26.7)$ & \\
\hline Moderate (3-6) & $6(20.0)$ & $9(30.0)$ & \\
\hline Severe $(7-10)$ & $5(16.7)$ & $5(16.7)$ & \\
\hline
\end{tabular}

*: Paired samples T test; **: Mann-Whitney U Test

Table 2: Study results separated by feedback status.
The mean percentage of incorrect movements in the sessions without feedback $43.3 \%$ and $11.4 \%$ in the sessions with feedback. This translates into a decrease in the probability of performing an incorrect repetition from 1:1.3 without biofeedback to 1:7.7 with biofeedback.

There was no difference between the range of motion in the sessions with or without biofeedback (Table 2).

In the sessions with feedback, both the total number of movements and the movement frequency were lower than in the sessions without feedback $(\mathrm{p}<0.01)$.

There was no difference in the number of pauses, posture errors, and range of motion variability over time (Table 2 ).

\section{Pain and fatigue}

There was no difference in terms of pain $(\mathrm{p}=0.69)$ or fatigue ( $\mathrm{p}=0.86)$ in both settings.

\section{Effect of session order in the primary outcome}

There was no influence of session order in the primary outcome, both in terms of the number of correct movements $(p=0.73)$ and regarding the magnitude of the biofeedback effect $(\mathrm{p}=0.23)$ (Table 3$)$.

\section{Exploratory analysis of the effect of clinical and demographic characteristics on the primary outcome}

The variation of the primary outcome between the sessions was not influenced by age $(\mathrm{p}=0.99)$, gender $(\mathrm{p}=0.60)$, education $(\mathrm{p}=0.16)$, NIHSS $(\mathrm{p}=0.92)$ and time from stroke onset $(\mathrm{p}=0.22)$.

No correlation was found between gender $(\mathrm{p}=0.99)$, education $(\mathrm{p}=0.77)$, NIHSS score $(\mathrm{p}=0.16)$ or time since stroke onset $(\mathrm{p}=0.81)$

\begin{tabular}{|l|c|c|l|}
\hline Feedback session first & Without feedback & With feedback & P value \\
\hline $\begin{array}{l}\text { Number of correct movements } \\
\text { Average (SD) }\end{array}$ & $34.1(24.9)$ & $42.3(19.5)$ & $0.02^{*}$ \\
\hline Feedback session second & & & \\
\hline $\begin{array}{l}\text { Number of correct movements } \\
\text { Average (SD) }\end{array}$ & $25.8(16.2)$ & $42.4(21.8)$ & $0.01^{*}$ \\
\hline
\end{tabular}

*Mann-Whitney $\cup$ Test

Table 3: Study results separated by study arm.
(A)

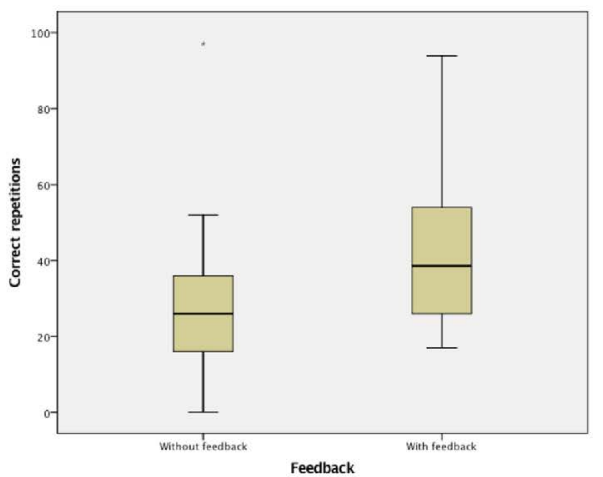

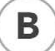

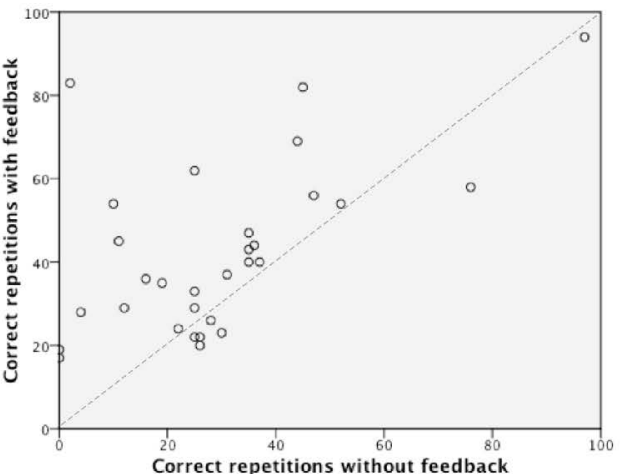

Figure 3: Comparison between the number of correct movements in the sessions with and without feedback. A) Comparison of the $95^{\text {th }} \mathrm{Cl}$ (Box-plot chart). B) Scatter plot; the difference between sessions is perceived by comparing the points to the diagonal "line of unity"- points above this line indicate better results in the sessions with feedback. 
and the number of correct movements. However, we found an inverse correlation between the number of correct movements and age $(\mathrm{p}=0.02)$.

Also, no correlation was found between gender $(\mathrm{p}=0.46)$, age $(\mathrm{p}=0.32)$, education $(\mathrm{p}=0.20)$, time from stroke onset $(\mathrm{p}=0.30)$ or NIHSS $(\mathrm{P}=0.81)$ and the variation of correct movements between the two sessions.

\section{Discussion}

This was an exploratory study on the impact of the audio-visual biofeedback provided by the SWORD system in the motor performance of patients after stroke. The previous version used a simple vibratory feedback, providing a stimulus that forced the patient to concentrate on reaching the goal of the task, while at the same time stimulating the somatosensory cortex in the affected hemisphere, which is known to be involved in cortical reorganization after stroke [32,33]. Vibratory feedback was subsequently changed for visual and auditory feedback, based on intrinsic limitations of this type of feedback, possible interference from the vibratory module on motion tracking and on neurobiological and experimental data demonstrating the benefits of visual and auditory feedback.

To compare both types of feedback, we performed a study with a similar design. Baseline demographic and clinical characteristics do not differ much between the two studies [25]. There were, however, two noteworthy differences: a) this study was performed in an outpatient setting (versus inpatient setting in the first); b) this study mainly included patients in the chronic stage (versus acute stage in the first, with a mean time from stroke onset to enrollment of 6.8 days).

In both studies, the number of correct movements in the sessions with feedback was higher and the probability of performing an error in the motor task lowers. However, in this study, movement and posture constraints were introduced, to account for patient compensation strategies, thereby increasing the difficulty of achieving a correct repetition and forcing the patient to concentrate on performing the movement correctly. This is especially relevant given the risk that selftaught compensatory behavioral strategies can have a detrimental impact on motor rehabilitation [34]. This also probably explains why the total number of movements in the sessions with feedback was lower, contrary to the previous one.

Also in both, results were similar when the feedback session was performed before or after the session without feedback, confirming the effect is attributable to the biofeedback and not to learning or aftereffects.

We speculate that the visual and auditory feedback probably works in a similar way to the vibratory feedback, forcing the patient to concentrate on the task while stimulating different cortical areas and potentially enhancing neuroplasticity, a view shared with other authors [35]. In this sense, this study confirms the findings that visual and auditory feedback can enhance motor performance [28].

Therefore, despite the fact that the two studies used different biofeedback, the results, when taken together, show a positive impact on patient performance both in the acute and chronic stage after stroke, in a subset of patients with mild motor impairment and no severe language or cognitive impairments. Further studies are necessary to confirm the impact of this system in the motor performance of a population with more severe deficits.

Based on the results of this study, there is room for further improvement on the system, namely: a) stimulating the patient to go beyond the target (provided this is not achieved by using compensation strategies); b) providing information on the type of movement error to help the patient correct wrong movements without external (therapist) input; c) improving gamification strategies to enhance engagement.

Pain and fatigue scores were similar in both sessions, and no adverse events were reported, demonstrating the safety of the system.

This study has several limitations that deserve comment. First, it was not sufficiently powered to detect differences regarding the majority of the secondary outcomes. Second, the session was limited to only one motor task, which is not a real clinical scenario. However, in our opinion, the results can be generalized to other motor tasks. Third, the duration of each session was short - $240 \mathrm{~s}$, but corresponds to typical duration of one exercise in a real-world scenario. Fourth, in this study, some important effects for clinical applications, namely retention and cumulative effect were not formally tested. Finally, there are limitations to the generalization of results due to the exclusion of patients with severe aphasia or complete upper-limb plegia and of patients with posterior circulation and hemorrhagic strokes.

As referred above, there is only anecdotal evidence of the use of IMUs in rehabilitation tools, with only two studies focused on upper limb rehabilitation $[23,24]$, the first being a case report and the second an open-label study involving eleven patients. Both studies addressed the viability and safety of IMU-based systems, as well as possible clinical benefits over the course of several sessions ( 7 in the case report and an average of 26.5 sessions in the open-label study). Plus, in both, the strategy used was one of pure gamification, whereas our strategy is more kinematic-oriented. Therefore, no direct comparison can be made between our study and these other two. Still, all three studies show that: a) IMU-based biofeedback systems represent a viable tool for upper-limb rehabilitation in stroke; b) they appear to be safe; c) they are practical and can be used independently by patients with minor/moderate paresis (namely in a home-based setting); and d) preliminary evidence shows positive impact on performance and on clinical outcomes.

\section{Conclusion}

This study validates the visual and auditory feedback provided by the current version of the system. While the magnitude of the effect of the current and previous (vibratory) feedback appears similar, this new feedback allowed the introduction of movement and posture constraints in a way that is perceptible for the patient, increasing the focus in movement quality.

Overall, the results are very encouraging and open the door to further research, namely to explore whether this system can be used to maximize rehabilitation outcomes after stroke. As stated before, there is a positive correlation between treatment intensity and functional outcomes [36], as well as a need for high-intensity, repetitive task-specific practice with feedback on performance [6]. In the current context of lack of appropriate access and insufficient treatment intensity [8,9], solutions like the one presented here can prove invaluable. Also, the experimental setting used provides preliminary evidence that with this system patient may be able to perform rehabilitation sessions independently. This is a possibility worth exploring, as it addresses the growing need for costeffective home-based rehabilitation solutions [37].

\section{Ethics Approval of Research}

The study was approved by the National Data Protection Commission and by the local ethics committee at Centro Médico da 
Murtosa, Murtosa, Portugal (Chair: Paulo Milheiro Maia, MD) and the methods were conducted in accordance with the approved guidelines. All patients and caregivers were provided with information about the purpose and procedures of the study and provided written informed consent before inclusion.

\section{Availability of Data and Materials}

The data that support the findings of this study are available from SWORD Health but restrictions apply to the availability of these data, which were used under license for the current study and so are not publicly available. Data are however available from the authors upon reasonable request and with permission of SWORD Health.

\section{Competing Financial Interests Statement}

FDC and VB have a shareholder position at SWORD Health, a company that develops and commercializes SWORD related products. $\mathrm{FS}, \mathrm{AB}$ and $\mathrm{AN}$ are employees of SWORD Health but do not have shareholder positions. CC, PQ and AA have no conflicts of interest to report.

\section{Funding}

This work was supported by the European Commission through the Project H2020 SME Instrument Phase 2 - Grant Agreement number 672814 .

\section{Authors' Contributions}

Study concept and design: FDC, VB, FS and AN. Acquisition of data: FS, CC, PQ, AA, Analysis and interpretation of data: FDC, AB, $A N, V B$. Critical revision of the manuscript for important intellectual content: All authors. Obtained funding: FDC, VB. Administrative, technical and material support: FDC, AB, FS, CC, PQ, AA. Study supervision: $\mathrm{FDC}, \mathrm{VB}, \mathrm{AB}, \mathrm{FS}, \mathrm{AN}$.

\section{Clinical Trial Registration}

This clinical trial was retrospectively registered at http://www. clinicaltrials.gov with the unique identifier: NCT03032692. Date of registration: 24 January 2017.

\section{References}

1. Mendis S, Puska P, Norrving B (2011) Global atlas on cardiovascular disease prevention and control. World Heal Organ, pp: 2-14.

2. Langhorne P, Coupar F, Pollock A (2009) Motor recovery after stroke: A systematic review. Lancet Neurol 8: 741-754.

3. Kelly-Hayes M, Beiser A, Kase CS, Scaramucci A, D'Agostino RB, et al. (2003) The influence of gender and age on disability following ischemic stroke: The Framingham study. J Stroke Cerebrovasc Dis 12: 119-126.

4. Bernhardt J, Thuy MNT, Collier JM, Legg LA, Author A, et al. (2009) Very early versus delayed mobilisation after stroke. Cochrane Database Syst Rev.

5. Ferrarello F, Baccini M, Rinaldi LA, Cavallini MC, Mossello E, et al. (2011) Efficacy of physiotherapy interventions late after stroke: A meta-analysis. J Neurol Neurosurg Psychiatry 82: 136-143.

6. Langhorne P, Bernhardt J, Kwakkel G (2011) Stroke rehabilitation. Lancet 377 : 1693-1702.

7. WHO (2006) Neurological disorders: A public health approach. Neurol Disord Public Health Challenges: 141-176.

8. Norrving B, Kissela B (2013) The global burden of stroke and need for a continuum of care. Neurology 80 : S5-12.

9. Meyer M, Foley N, Pereira S, Salter K, Teasell R (2012) Organized stroke rehabilitation in Canada: Redefining our objectives. Top Stroke Rehabil 19: 149-57.
10. Resquín F, Cuesta Gómez A, Gonzalez-Vargas J, Brunetti F, Torricelli D, et al. (2016) Hybrid robotic systems for upper limb rehabilitation after stroke: A review. Med Eng Phys 38: 1279-1288.

11. Sheng B, Zhang Y, Meng W, Deng C, Xie S (2016) Bilateral robots for upperlimb stroke rehabilitation: State of the art and future prospects. Med Eng Phys 38: 587-606.

12. Kwakkel G, Kollen BJ, Krebs HI (2008) Effects of robot-assisted therapy on upper limb recovery after stroke: A systematic review. Neurorehabil Neural Repair 22: 111-121.

13. Wagner TH, Lo AC, Peduzzi P, Bravata DM, Huang GD, et al. (2011) An economic analysis of robot-assisted therapy for long-term upper-limb impairment after stroke. Stroke 42: 2630-2632.

14. Webster D, Celik O (2014) Systematic review of kinect applications in elderly care and stroke rehabilitation. J Neuroeng Rehabil 11: 108.

15. Cheok G, Tan D, Low A, Hewitt J (2015) Is Nintendo Wii an effective intervention for individuals with stroke? A systematic review and meta-analysis. J Am Med Dir Assoc 16: 923-932.

16. da Silva Ribeiro NM, Ferraz DD, Pedreira É, Pinheiro Í, da Silva Pinto AC et al. (2015) Virtual rehabilitation via Nintendo Wii ${ }^{\circledR}$ and conventional physica therapy effectively treat post-stroke hemiparetic patients. Top Stroke Rehabil 22: 299-305.

17. Tsekleves E, Paraskevopoulos IT, Warland A, Kilbride C (2014) Development and preliminary evaluation of a novel low cost VR-based upper limb stroke rehabilitation platform using Wii technology. Disabil Rehabil Assist Technol, pp: 1-10.

18. Cuesta-Vargas Al, Galán-Mercant A, Williams JM (2010) The use of inertial sensors system for human motion analysis. Phys Ther Rev 15: 462-473.

19. Zhang J-T, Novak AC, Brouwer B, Li Q (2013) Concurrent validation of Xsens MVN measurement of lower limb joint angular kinematics. Physiol Meas 34: 63-69.

20. Gil-Agudo Á, de los Reyes-Guzmán A, Dimbwadyo-Terrer I, Peñasco-Martín B, Bernal-Sahún A, et al. (2013) A novel motion tracking system for evaluation of functional rehabilitation of the upper limbs. Neural Regen Res 8: 1773-1782.

21. Li HT, Huang JJ, Pan CW, Chi HI, Pan MC (2015) Inertial sensing based assessment methods to quantify the effectiveness of post-stroke rehabilitation. Sensors (Basel) 15: 16196-16209.

22. Byl N, Zhang W, Coo S, Tomizuka M (2015) Clinical impact of gait training enhanced with visual kinematic biofeedback: Patients with Parkinson's disease and patients stable post stroke. Neuropsychologia 79: 332-343.

23. Samuel GS, Choo M, Chan WY, Kok S, Ng YS (2015) The use of virtual realitybased therapy to augment post stroke upper limb recovery. Singapore Med J 56: $127-130$.

24. Wittmann F, Held JP, Lambercy O, Starkey ML, Curt A, et al. (2016) Selfdirected arm therapy at home after stroke with a sensor-based virtual reality training system. J Neuroeng Rehabil 13:75.

25. Cruz VT, Bento V, Ruano L, Ribeiro DD, Fontão L, et al. (2014) Motor task performance under vibratory feedback early post stroke: Single center, randomized, cross-over, controlled clinical trial. Sci Rep 4: 5670.

26. Cramer SC (2008) Repairing the human brain after stroke: I. Mechanisms of spontaneous recovery. Ann Neurol 63: 272-287.

27. Nelson LA (2007) The role of biofeedback in stroke rehabilitation: Past and future directions. Top Stroke Rehabil 14: 59-66.

28. Parker J, Mountain G, Hammerton J (2011) A review of the evidence underpinning the use of visual and auditory feedback for computer technology in post-stroke upper-limb rehabilitation. Disabil Rehabil Assist Technol 6: 465-472.

29. Bonita R, Beaglehole R (1988) Modification of Rankin scale: Recovery of motor function after stroke. Stroke 19: 1497-1500.

30. Brott T, Adams HP, Olinger CP, Marler JR, Barsan WG, et al. (1989) Measurements of acute cerebral infarction: A clinical examination scale. Stroke 20:864-870.

31. Folstein MF, Robins LN, Helzer JE (1983) The mini-mental state examination Arch Gen Psychiatry 40: 812.

32. Brown CE, Aminoltejari K, Erb H, Winship IR, Murphy TH (2009) In vivo voltagesensitive dye imaging in adult mice reveals that somatosensory maps lost to 
Citation: Correia FD, Santos F, Branquinho A, Nogueira A, Candeias C, et al. (2017) Motor Task Performance under Visual and Auditory Feedback Post Stroke: A Randomised Crossover Trial. Int J Neurorehabilitation 4: 291. doi: 10.4172/2376-0281.1000291

stroke are replaced over weeks by new structural and functional circuits with prolonged modes of activation within both the peri-infarct zone and distant sites. J Neurosci 29: 1719-1734.

33. Clarkson AN, López-Valdés HE, Overman JJ, Charles AC, et al. (2013) Multimodal examination of structural and functional remapping in the mouse photothrombotic stroke model. J Cereb Blood Flow Metab 33: 716-723.

34. Jones TA, Adkins DL (2015) Motor system reorganization after stroke: Stimulating and training toward perfection. Physiology 30:358-370.
35. Yates M, Kelemen A, Sik LC (2106) Virtual reality gaming in the rehabilitation of the upper extremities post-stroke. Brain Inj 30: 855-863.

36. Cooke EV, Mares K, Clark A, Tallis RC, Pomeroy VM, et al. (2010) The effects of increased dose of exercise-based therapies to enhance motor recovery after stroke: A systematic review and meta-analysis. BMC Med 8: 60

37. Hillier S, Inglis-Jassiem G (2010) Rehabilitation for community-dwelling people with stroke: Home or centre based? A systematic review. Int J Stroke 5: 178186. 